\title{
The Development of an Integrally Geared Centrifugal Compressor
}

\author{
Cheng Xu ${ }^{1,2}$, Hanqian Yang ${ }^{1, ~ *, ~ Y a n d a n ~ J i a n g ~}{ }^{1}$, Zhongwei Yi ${ }^{1}$ \\ ${ }^{1}$ Department of Mechanical and Electrical Engineering, Central South University of Forestry and Technology, Changsha, China \\ ${ }^{2}$ Department of Mechanical Engineering, University of Wisconsin, Milwaukee, USA
}

Email address:

yhanqian@sina.com (Hanqian Yang)

${ }^{*}$ Corresponding author

\section{To cite this article:}

Cheng Xu, Hanqian Yang, Yandan Jiang, Zhongwei Yi. The Development of an Integrally Geared Centrifugal Compressor. International Journal of Fluid Mechanics \& Thermal Sciences. Vol. 5, No. 1, 2019, pp. 1-9. doi: 10.11648/j.jjfmts.20190501.11

Received: September 26, 2018; Accepted: April 8, 2019; Published: May DD, 2019

\begin{abstract}
Integrally geared centrifugal compressors have been widely used in industry especially. Reliable design, good performance, low noise, no resonant frequencies in the operating range and cost effective machining and casting parts are the goals of the design. Computational Fluid Dynamics (CFD) tools have been widely used to optimize the impeller, diffuser and volute designs. Many design considerations are useful for compressor preliminary parameter selections and compressor package designs. In this paper, the detailed development and design of a integrally geared centrifugal compressor are discussed. Some initial design considerations for compressor configureuration, power distribution for each stage, and possible field application issues are discussed in details. The aerodynamic and structural optimization using CFD and Finite Element Analysis (FEA) are performed to obtain a high efficiency and wide operating range compressor with robust operation. The new compressor development process addressed in this paper provides the basic design guidance for future new integrally geared compressor development.
\end{abstract}

Keywords: Centrifugal Compressor, Compressor Design Consideration, CFD

\section{Introduction}

The integrally geared centrifugal compressor is one of the important types of turbomachines to increase the gas pressure [1-8]. Integrally geared centrifugal compressors have more advantages than direct drive compressor because impellers can rotated in a higher tip speed. The power density of the integrally geared centrifugal compressors is higher than direct driven compressors. The integrally geared centrifugal compressors have small compressor frames and low capital expenditures. Its applications can be in a way of single stage or multi-stages for gas compression. The integrally geared centrifugal compressors have wide applications in process and air separation industries. Due to the high rotating speed of the geared compressor, the semi-open unshrouded impellers are always used. The unshrouded impellers have advantages in manufacturing but bring extra tip clearance aerodynamic losses. The tip clearance losses are related to each impeller loading and impeller design. The design experience of the stage power distributions can help designers to get reasonable stage loading in short time. This paper will discuss in details of design experience.

Recent progress being made on the development of small capacity high-speed direct drive compressors [9], however, the high cost in high-speed motor only allows them to use in some of the premium applications. The geared centrifugal compressors are very popular in industrial applications. The geared centrifugal compressor design process has been discussed for years [3]. However, there is no standard process can be used for modern industrial gear compressor designs. The modern centrifugal compressor design process still needs to further develop.

The air separation industrial grows rapidly recently due to the industrial needs of pure Oxygen and nitrogen. In air separation process, air compressors draw the air and compress it to a certain pressure before it is cooled and separated into its main constituents. The gas was separated into oxygen and nitrogen and then be compressed and fed into a pipeline. Cryogenic air separation compressors are one 
of the high-energy consumption devices in air separation plants. The utility cost of the air compressors is the primary energy consumer of an air separation process. The energysaving opportunities have been studied extensively [10]. For the air separation plant, the system demands for compressed air are not always same. Sometime the system airflow can be less than $50 \%$ of the maximum flow capability. The variations of the airflow demands require compressor turndown as much as $50 \%$. It is necessary to develop a high efficient and wide operating range compressor. This paper authors present a detail compressor design process from marketing requirement to final design. It will be a good reference for compressor manufacturers.

In this paper, the centrifugal compressor design process and development method were presented in detail through a geared centrifugal compressor development. The compressor developed here is an integrally geared four stage centrifugal compressor with the total-to-static pressure ratio of 12 and inlet volumetric flow of $7.3 \mathrm{~m}^{3} / \mathrm{s}$. The reliable, higher performance, large surge margin, low noise, no resonant frequencies in the operating range and economic to manufacture are the goals of the design. The detail processes for this integrally geared centrifugal compressor developments are discussed in this paper. The integral thinking and optimization used in this design process can serve as a guideline for future compressor developments.

While CFD and FEA are widely used in the compressor design, many detail compressor design considerations and optimizations can accelerate the design before CFD and FEA optimizations [2-20]. The compressor stage design, analysis and optimization are similar for all stages. The detail design processes and aerodynamic analysis are presented here by using first stage as an example.

\section{Preliminary Design Considerations}

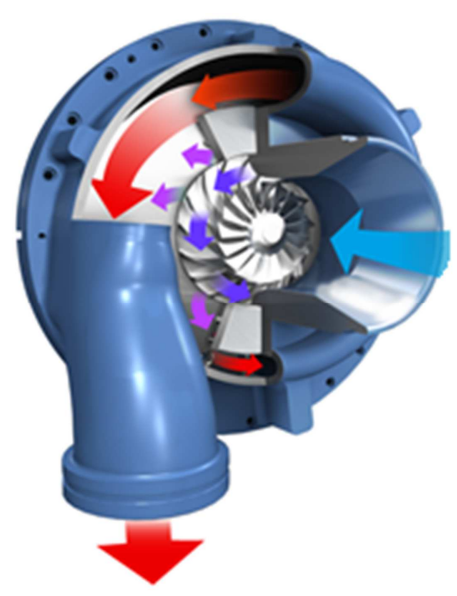

Figure 1. Centrifugal compressor.

A typical single stage compressor is shown in Figure 1. The gas enters a centrifugal compressor in axial direction. As the gas continues to pass into centrifugal impeller, the impeller forces the gas flow to increase the kinetic energy and static pressure. The work input to gas by impeller is proportional to impeller diameter and impeller rotational speed. In most of the cases, the gas leaves the impeller then enters a vaned or vanless diffuser to decelerate the gas to increase the static pressure. The compressed gas finally enters a scroll or collector and then delivers to applications or next stage.

The compressor design processes normally started with the performance and cost target optimizations. The life time cost of the compressor includes the capital cost, i.e. the cost for purchasing the compressor; and the annual operational cost, i.e. the cost of the compressor energy consumption. The new compressor design needs to make sure that the end users have a lowest lifetime cost. The optimizations and considerations for the compressor manufacturing cost and operational cost are normally done by compressor manufacturing based on inhouse experience and database. Most of the current method for new compressor design is scale and modify the previous design to a new design and then do the optimization in the components [1, 15]. A few academic studies have been done to mention to combine the detail compressor design considerations and optimizations; there are very limited publications in this area. The authors have discussed the importance of some of the design considerations in the past studies [1, 16]. In this paper, the detail new compressor development process and considerations are discussed.

In this paper, a centrifugal compressor is developed for air separation applications. The air separation customers use both engines and motors to drive the compressors. For this size of machine, the customers are most likely to use an electric motor to drive compressors. Therefore, the choice of different poles of the motor is important. The studies between two-pole and four-pole motor are conducted based on the cost and performance trade-off studies. To effectively study the motor selection, it is necessary to determine numbers of stages. Based on some of the design consideration and manufacturing cost analysis [1], the annual operation and capital cost vs number of compressor stages are shown in Figure 2. It is shown that three and four stages for this machine are good choices. Considering the applications need $10 \%$ more pressure ratio in some of the applications, four stages are used for this compressor design.

The historical in-house manufacturing compressor cost for both two-pole and four-pole motors for different compressor design inlet flow are shown in Figure 3. It can be seen than the two-pole motor drivers are used for small compressors. For the compressor size in this study, we can use both twopole and four-pole motors. Figure. 3 shows that the initial aerodynamic components (impeller, impeller housing, scroll, and diffuser) cost using four-pole motor is about $80 \%$ more than two-pole motor. The performance penalty using twopole motor is about $1.9 \%$ using in-house analysis system [3, 4]. Based on the current energy cost information, a $2500 \mathrm{~kW}$ machine will increase operation cost about $\$ 180,000$ for two years which is more than the total cost of aerodynamic components. Based on the hardware cost and operation cost information, it is obvious that the customers prefer the four pole motor design. The compressor developed here uses four- 
pole motor.

This integrally geared compressor is chosen to have two pinions with two stages in each pinion. The stage power distributions are critical for cost and performance. The cost and efficiency trade off studies are conducted. The studies for power split in two pinions are conducted. The manufacturing cost and performance impacts for different power splits are shown in Figure 4. It is demonstrated that a low speed pinion load of about $52 \%$ of the overall power is good for both compressor performance and manufacturing cost.

The selection of flow coefficient at compressor design point is important for both compressor efficiency and aerodynamic components' cost. Normally, the cost of the aerodynamic components is about $35 \%$ of the whole compressor system cost. An in-house cost database and performance estimation program is used to predict the performance and compressor cost impacts [3, 4]. The manufacturing cost of the aerodynamic components is calculated based on the size of the impeller, diffuser and scroll for different flow coefficient as shown in Figure 5. The cost ratio is the cost versus the cost of airend with best aerodynamic efficiency. It is shown that flow coefficient around 0.08 is good for both aerodynamic performance and cost.

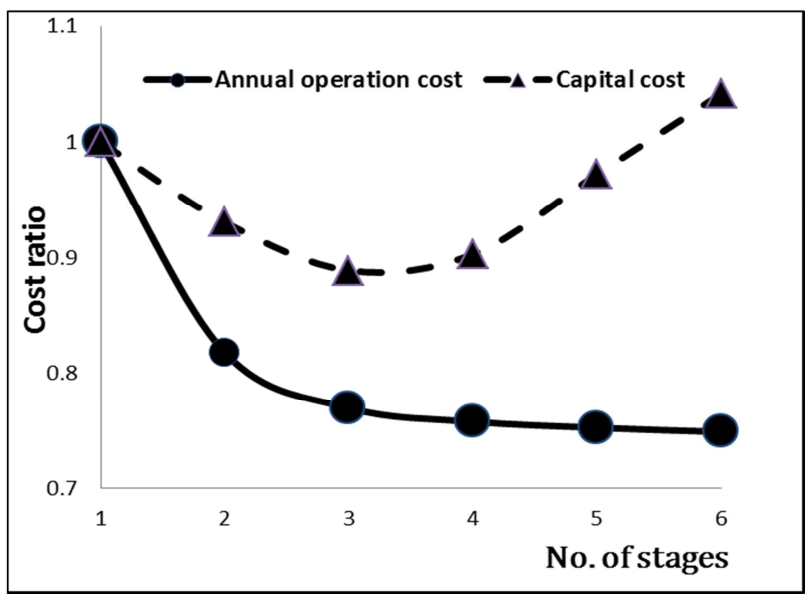

Figure 2. The number of stage selections.

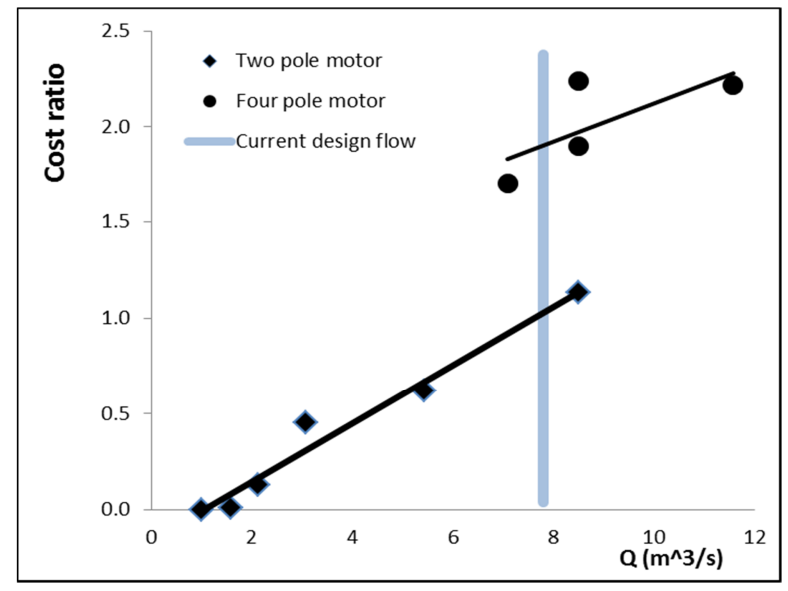

Figure 3. Motor selections.

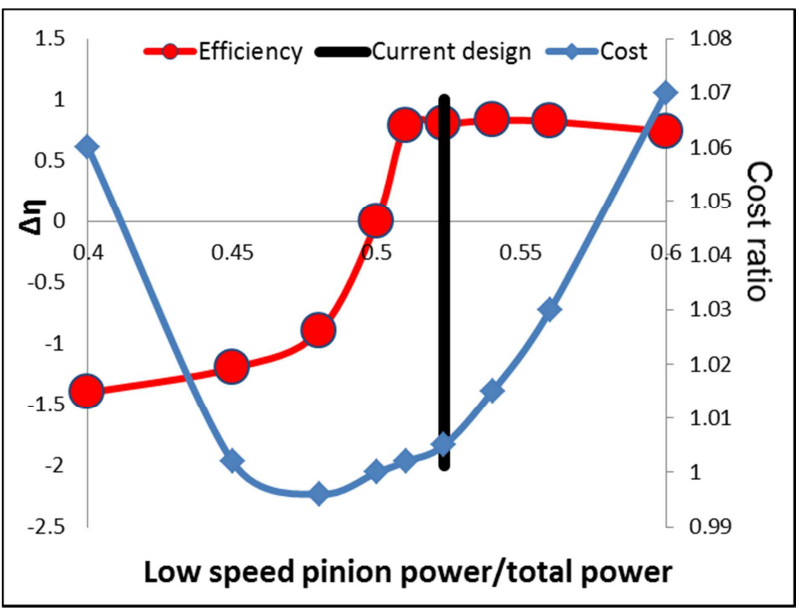

Figure 4. Performance and cost Vs power split.

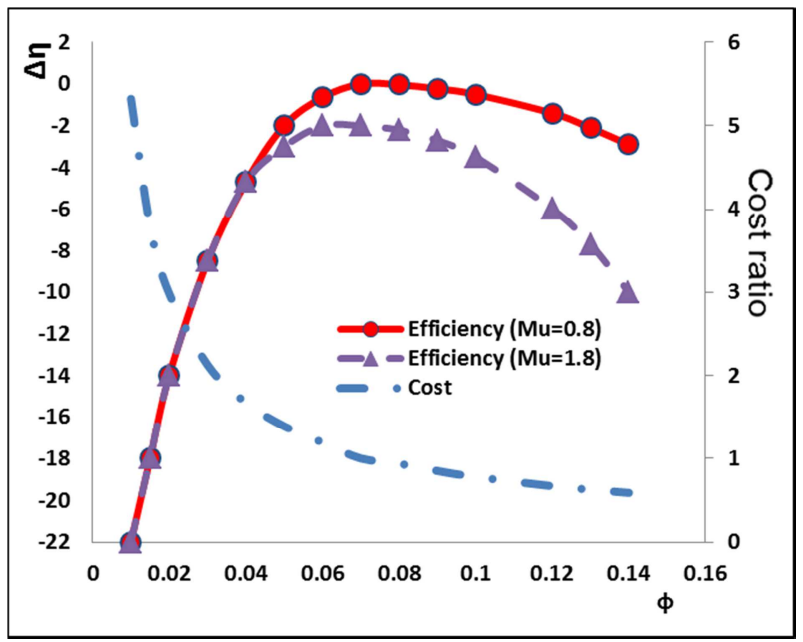

Figure 5. Flow coefficient Vs cost and performance.

The power distributions of each pinion are determined by the flow coefficient requirements of each stage. With certain flow coefficients, the pinions need to have certain speeds to transfer designed power to gas. It is necessary to check whether the power and speed combination in each pinion is within the manufacturing experience and capability. Compressors developed in the past are always a good reference for new development. The experience demonstrates that once the pinion power is within a certain range for a given pinion speed, no need special material or treatment are needed for the pinion and bull-gear; otherwise the manufacturing cost could increase significantly. The study results are shown in Figure6. It is shown that the pinion cost and manufacturing method are within past low cost experience for current design.

The impeller back sweep angle is also one of the parameters which need to be determined before starting the detail design of the impeller. The work input of the impeller can be expressed in term of back sweep angle as

$$
\Delta \mathrm{h}=\mathrm{u}_{2}^{2}-\mathrm{C}_{\mathrm{s}} \mathrm{u}_{2}-\mathrm{C}_{\mathrm{r} 2} \mathrm{u}_{2} \tan \beta_{2}
$$

Where the slip velocity can be expressed as [21] 


$$
\mathrm{C}_{\mathrm{s}}=\mathrm{u}_{2}\left(\cos \beta_{2}\right)^{0.5} \mathrm{Z}^{0.7}
$$

It can be seen from eq(1) that the large back sweep angle reduces the work input of the impeller. For same stage pressure ratio, larger back sweep angle impeller needs bigger diameter than the small back sweep impeller. However, the larger sweep angle has a beneficial on reducing the impeller discharge Mach number. A small impeller discharge Mach number improves the compressor efficiency and operating range. In this study, the back sweep angle was initially set between $40^{\circ}$ to $50^{\circ}$ to perform the optimization considering both cost and efficiency [1]. The final average blade sweep angle was set about $46^{\circ}$ to have the best combination of benefits for both performance and impeller cost.

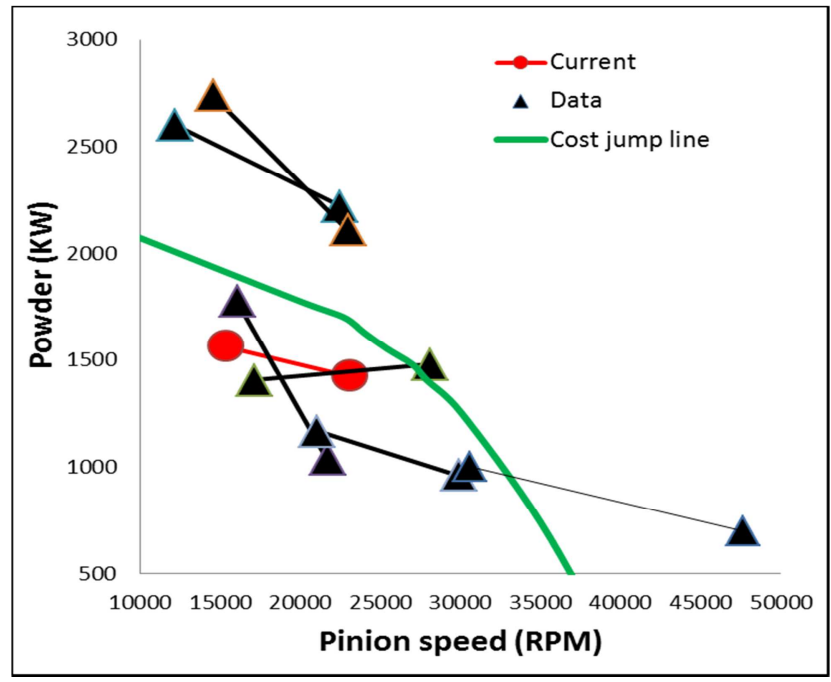

Figure 6. Design experience for pinion speed.

\section{Compressor Design and Optimization}

After the initial and preliminary considerations, the detailed aerodynamic and structure optimizations are conducted. The centrifugal compressor design normally starts with meanline optimization [1-3], and then moves to detail designs of the individual components. A turbomachinery design system combined with a number of tools has been successfully used in the past for centrifugal compressor development [13]. The preliminary meanline design tool is used to optimize the compressor one-dimensional parameters. In this study, a similar design process has been used for this new compressor design. Before the three-dimensional CFD optimizations, the meanline tool is used to optimize the design parameters of the impeller, diffuser and scroll. Based on the primary parameters set by meanline tool, the shape of the impeller blades and flow channels are modified until an optimal geometry is found. The detail design process is shown in Figure7.

The detailed aerodynamic design process for each stage is same for all four compressor stages. This paper only presents the detail information of the first stage design. The first stage rotational speed is about $23,000 \mathrm{RPM}$, the design total to static pressure ratio is 2.05 . The inlet pressure is $99.0 \mathrm{kpa}$ and temperature is $308.15^{\circ} \mathrm{K}$.

Three-dimensional CFD analysis has been extensively used in centrifugal compressor designs [12-21]. Most turbomachinery design systems use extensive RANS threedimensional equations for CFD. In structure analysis, FEA and frequency analyses are commonly used in an iterative manner with CFD during the design. It this study, a commercial code from Ansys CFX [22] and Ansys structure [23] are used for CFD analysis and structure design optimization. During the impeller design, the structure and aerodynamic optimizations are performed to produce a reliable design with good performance. The low solidity diffusers are used in all stages to produce the wide operating range of the compressor $[1,2]$.

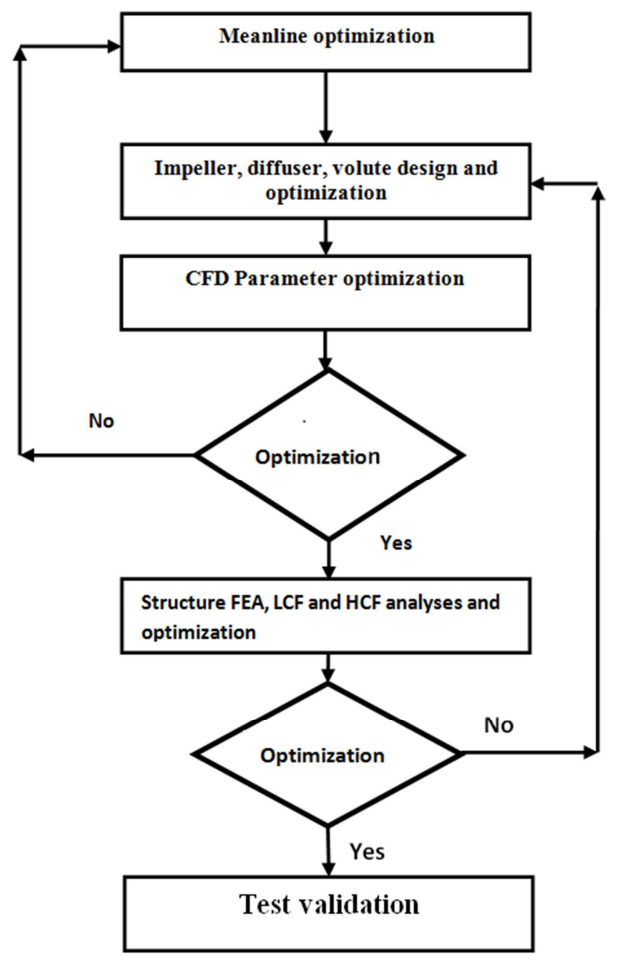

Figure 7. Centrifugal compressor design process.

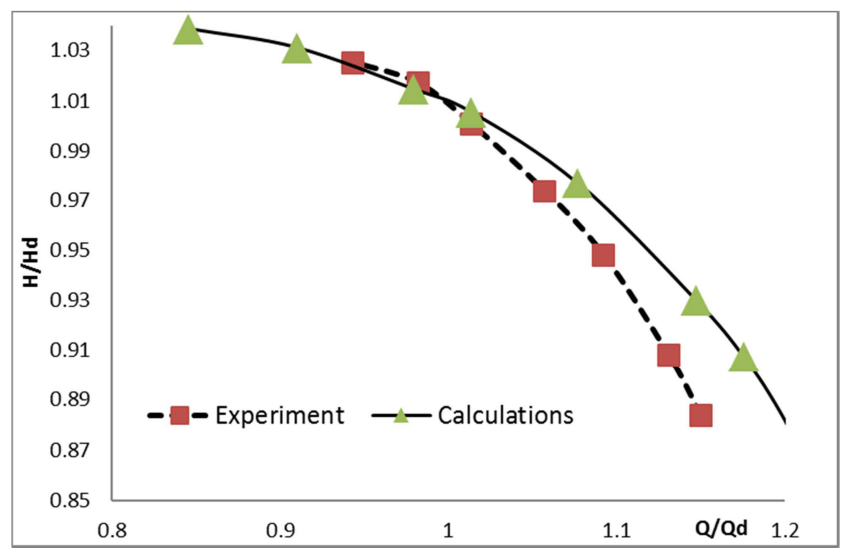

Figure 8. Non-dimensional Head comparison between experiment and calculations. 


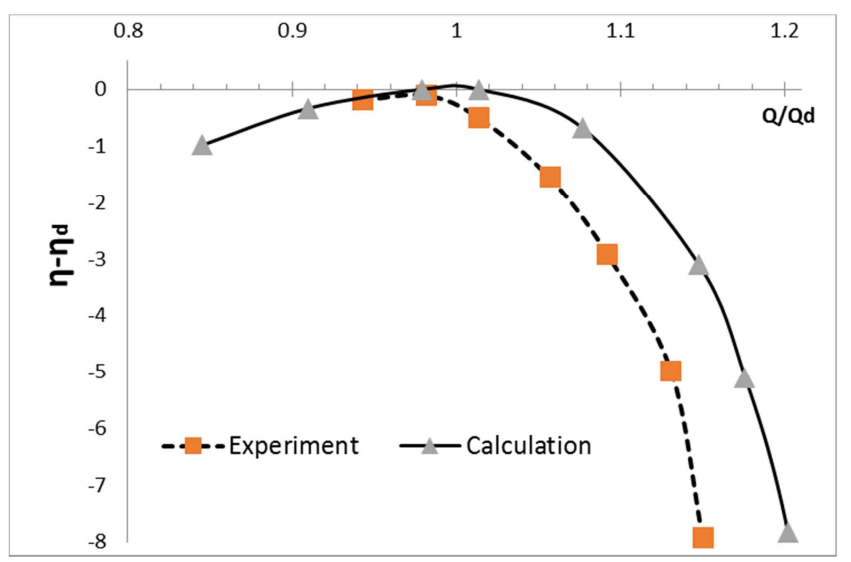

Figure 9. Non-dimensional efficiency comparison between experiment and calculations.

The aerodynamic optimizations for impeller, diffuser and scroll are very important to provide the compressor stage with good efficiency and wide operation range [5-12]. CFD is one of the important tools to predict the performance of each design iteration. The mesh independence and sensitivity is critical during design iterations to make sure that analyses can predict the design performance without the impacts of the mesh sizes. In this study, hexahedron meshes are used in all CFD calculations. The hexahedron meshes were generated by using Ansys ICEM [22]. All the endwall mesh are adjusted to make sure the $y+$ value is less than 1 to make sure the CFD calculations converge and agree with empirical results of past CFX analysis experience [4-7]. The mesh count independence and sensitivity studies are conducted [14] basis the five levels of impeller and vane meshes and three levels of the scroll meshes. The goal of the mesh independence studies is to have less than $0.05 \%$ change in efficiency and $0.1 \%$ change in mass flow of the compressor when the mesh size changes. Once the mesh count independence studies are completed, the mesh temperate is kept the same for all CFD studies to reduce the mesh cell structure sensitivity. The number of mesh nodes in the impeller, vaned diffuser and scroll are about 1.5, 1.2 and 4.5 million, respectively. These mesh sizes agree with past experience $[4,5]$. Previous CFD experience for different centrifugal compressors with a similar type of mesh demonstrated that CFD predicts the centrifugal compressor performance within typical test tolerances $[4,5]$. The CFD verification by using the existing compressor stage were performed. The CFD results were compared with experiment are shown in Figure 8 and 9. It can be seen that CFD provided a good simulations when the compressor operated near the design point.For this design process, the past experience of the CFD were used. A typical CFD mesh is shown in Figure10.

The lean of the impeller has significant impacts of the compressor performance [16]. Previous studies [16] indicated that negative lean improves the peak efficiency and positive lean can improve the operating range. In this study, the peak efficiency is more critical for the application. The negative $4^{\circ}$ lean design is chosen for the final design.

The final designed stage streamline from CFD is shown in Figure 11. It can be seen that the flow inside of the compressor does not have any flow separation. The design target is set to have $87 \%$ stage efficiency. The CFD calculation results of the compressor stage are shown in Figure12. It can be seen that the peak isentropic total to static stage efficiency is about $87.6 \%$ which exists the design target of $87 \%$.

From time to time, the impeller failures are one of the most important damage of the centrifugal compressor. Impellers not only undergo the centrifugal force due to high speed rotating and aerodynamic forces but also get excitation from aerodynamics vibration and other vibrations. For the final impeller design, the structure and vibration analyses are necessary to make sure the impeller is reliable. The impeller is made by using $17-4 \mathrm{PH}$ stainless steel. The main mechanical properties of 17-4PH stainless steel are shown in Table 1 [24]. The FEA stress calculation result is shown in Figure 13. It can be seen that the maximum von Mises stress stress of the impeller at design rotating speed is below $137 \mathrm{ksi}$ (944.6 Mpa). The maximum stress location is at blade filet. And it is lower than 17-4 PH H1150 stainless steel yield stress of $150 \mathrm{ksi}(1034 \mathrm{Mpa})$. The stress level meets the design standard. The interference diagram for six IGV airfoils and thirteen diffuser vanes is shown in Figure 14. It is shown that it doesn't have any frequency excitation problem for both IGV and diffuser.

Table 1. Typical 17-4 PH mechanical properties [24].

\begin{tabular}{llllllll}
\hline Property & A & H900 & H925 & H1025 & H1075 & H1150 & H1150-M \\
\hline UTS, MPa & 1103 & 1448 & 1379 & 1276 & 1207 & 1103 & 1034 \\
0.2\%YS, MPa & 1000 & 1379 & 1345 & 1172 & 1148 & 1034 & 896 \\
Elongation,\%in 50.8 mm & 5.0 & 7.0 & 8.0 & 8.0 & 8.0 & 11.0 & 12.0 \\
Hardness, Rockwell & C35 & C45 & C43 & C38 335 & C37 & C35 & C33 \\
\hline
\end{tabular}

The rotor vibrations cause the impeller and other compressor component failure. The rotordynamicanalysis for pinion with impellers are critical to avoid the rotor system vibration issues. The extensive iterations for bearing and pinion design through rotordynamic analyses were performed. The final design meet the design requirements. The damped unbalanced response analysis with maximum and minimum bearing clearances is shown in table 2 . The pinion speed is about 23000RPM. The smallest range for $2^{\text {nd }}$ and $3^{\text {rd }}$ mode is at maximum bearing clearance. This range is between 11908 RPM and 26888 RPM. It is shown that the compressor pinion is operated between $2^{\text {nd }}$ mode speed and $3^{\text {rd }}$ mode speed. There is enough separation margin between operational speed and nature frequencies. 
Table 2. Damped natural frequencies at design pinion speed.

\begin{tabular}{lllllll}
\hline & First mode LogDec & $\begin{array}{l}\text { Rotating } \\
\text { speed }\end{array}$ & $\begin{array}{l}\text { Second mode } \\
\text { LogDec }\end{array}$ & Rotating speed & $\begin{array}{l}\text { Third mode } \\
\text { LogDec }\end{array}$ & $\begin{array}{l}\text { Rotating } \\
\text { speed }\end{array}$ \\
\hline Maximum bearing clearance & 0.695 & 7677 & 0.474 & 11908 & 7.949 & 2688 \\
Minimum bearing clearance & 0.672 & 7090 & 0.513 & 11523 & 4.609 & 28714 \\
\hline
\end{tabular}

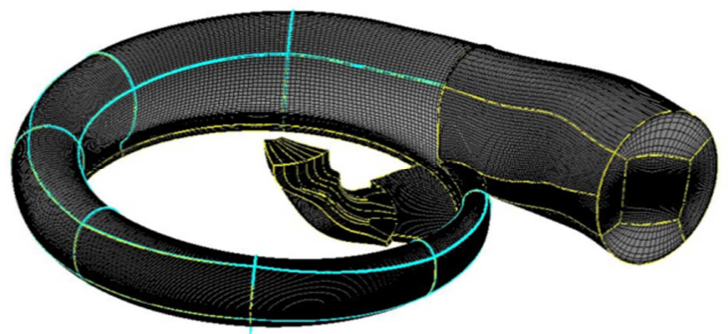

Figure 10. Computational mesh.

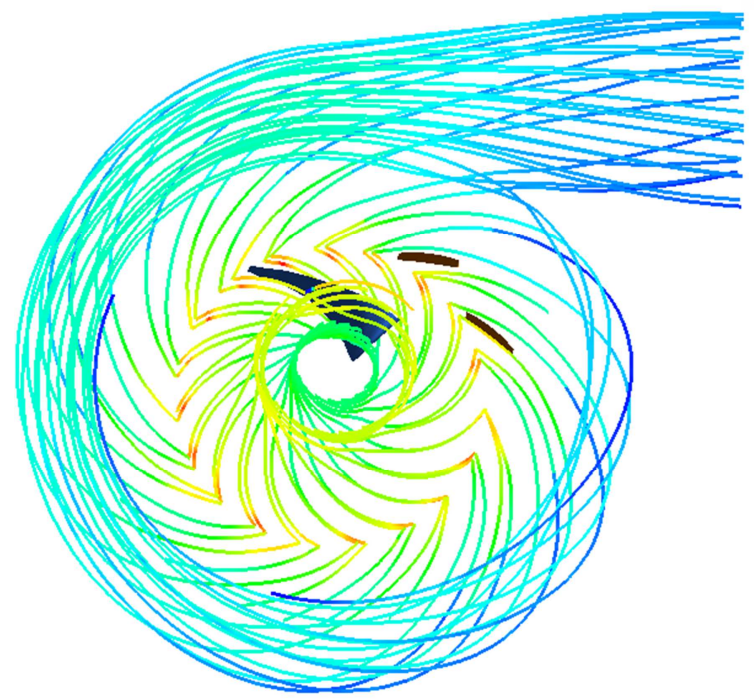

Figure 11. Streamlines from CFD.

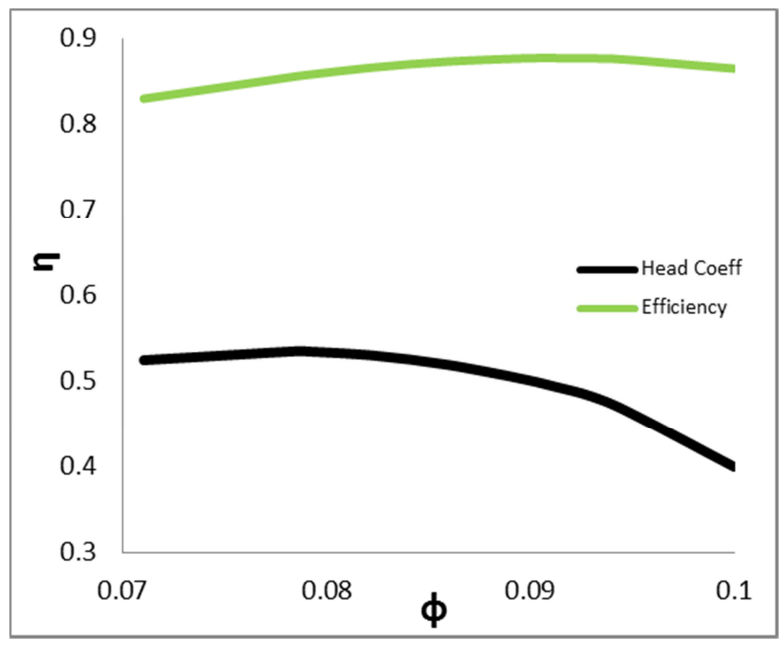

Figure 12. Efficiency and head coefficient.

\section{Analysis of the Potential Field Issue}

The new compressor development not only needs have reliability and good performance, but also possible field issues must predict. It is a good practice to analyze the potential application issues or misuse problems. In this paper, the authors present one of the many analyses for potential field impacts as an example to address one of the field issues through analysis.

Due to the cost reason, some of the customers want to use Aluminum diffuser vanes for their applications. However, harmful vapor contaminants including sulfides and chlorides are often found near salt water coastal locations. The harmful vapors can cause diffuser blade erosion and corrosion. As a result, the compressor performance will degrade. After finishing the compressor design, the performance impacts of the diffuser corrosion and erosion are analyzed. The CFD geometry for eroded diffuser shape based on the typical field application after five years running of the compressor is shown in Figure15. The compressor performance impacts from the erosion and corrosion from CFD compared with new diffuser are shown in Figure. 16 and 17. It demonstrates from Figure 16 that the peak efficiency point moves toward to the lower flow coefficient. The stage efficiency at design flow coefficient drops about $0.4 \%$. The efficiency drops more at low flow coefficients. Figure 15 demonstrates that the stage pressure also drops about 3\% at design flow. The pressure drop of one stage impacts the stage matching for the overall compressor. The compressor power consumption of the compressor unit will increase about $1.1 \%$ due to first stage diffuser erosion and corrosion. Studies suggested after five years operation, the Aluminum diffuser should be replaced by a new diffuser to keep the good compressor unit performance.

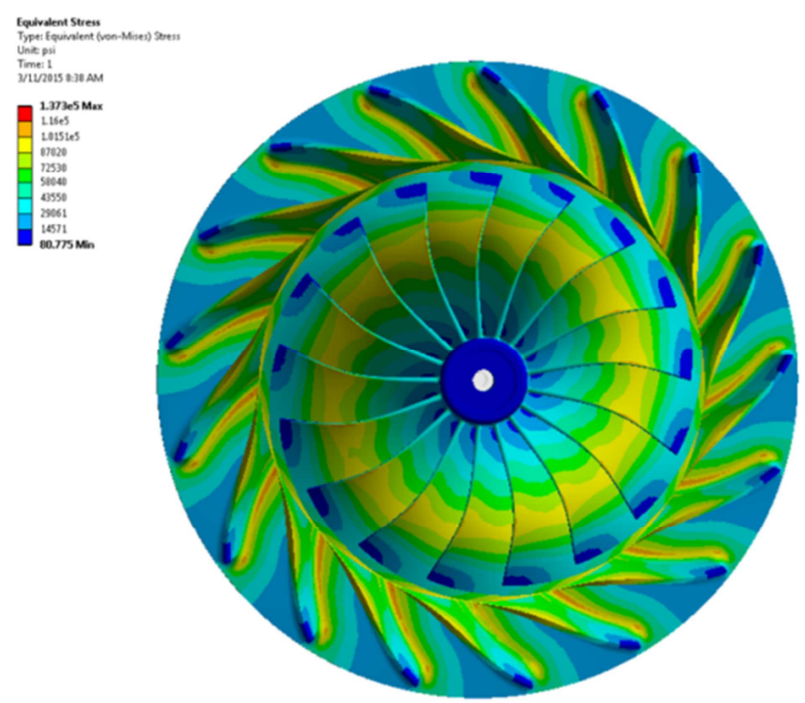

Figure 13. Stress analysis results. 


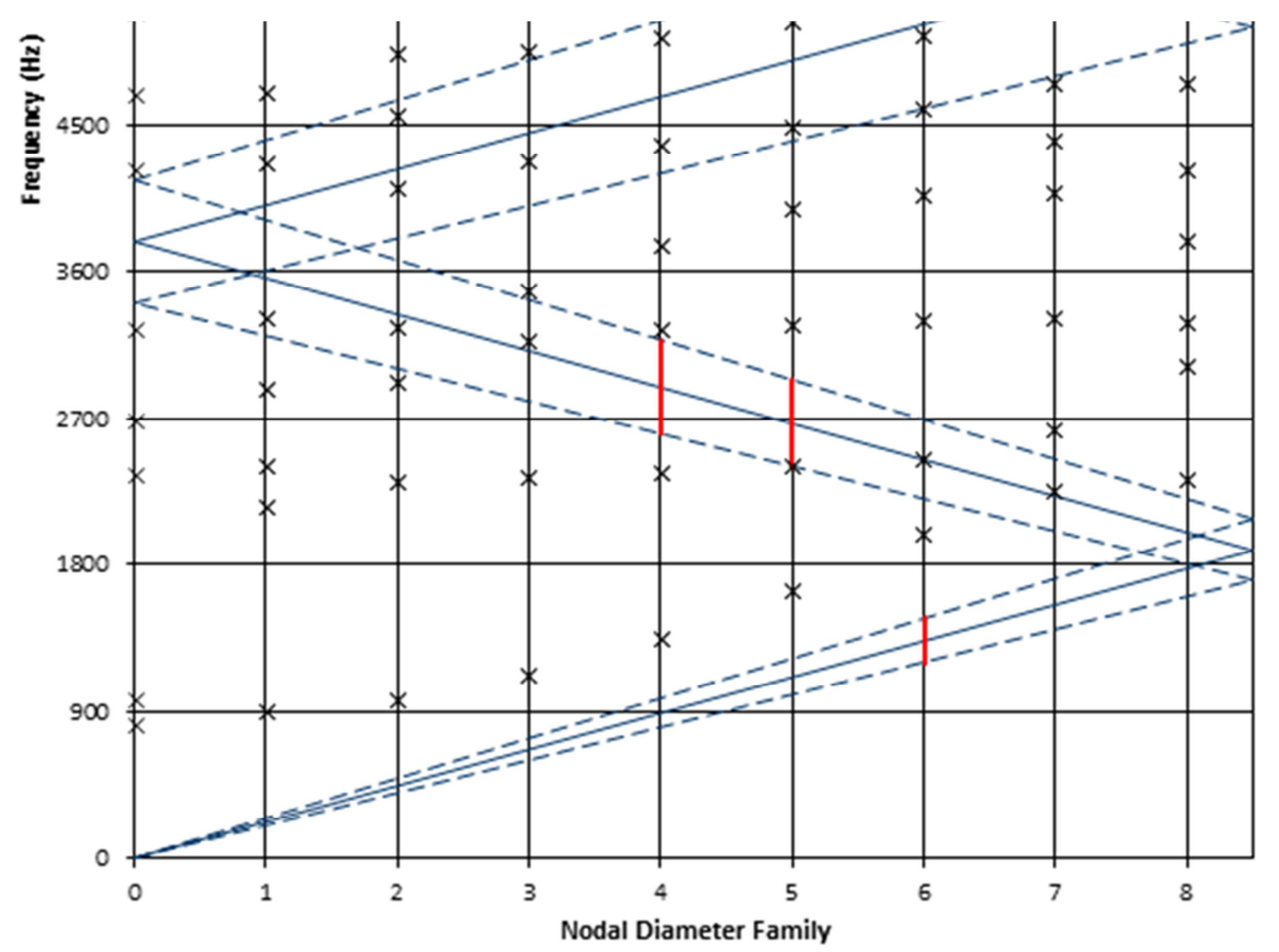

Figure 14. Interference diagram for 6 IGV airfoils and 13 diffusers.

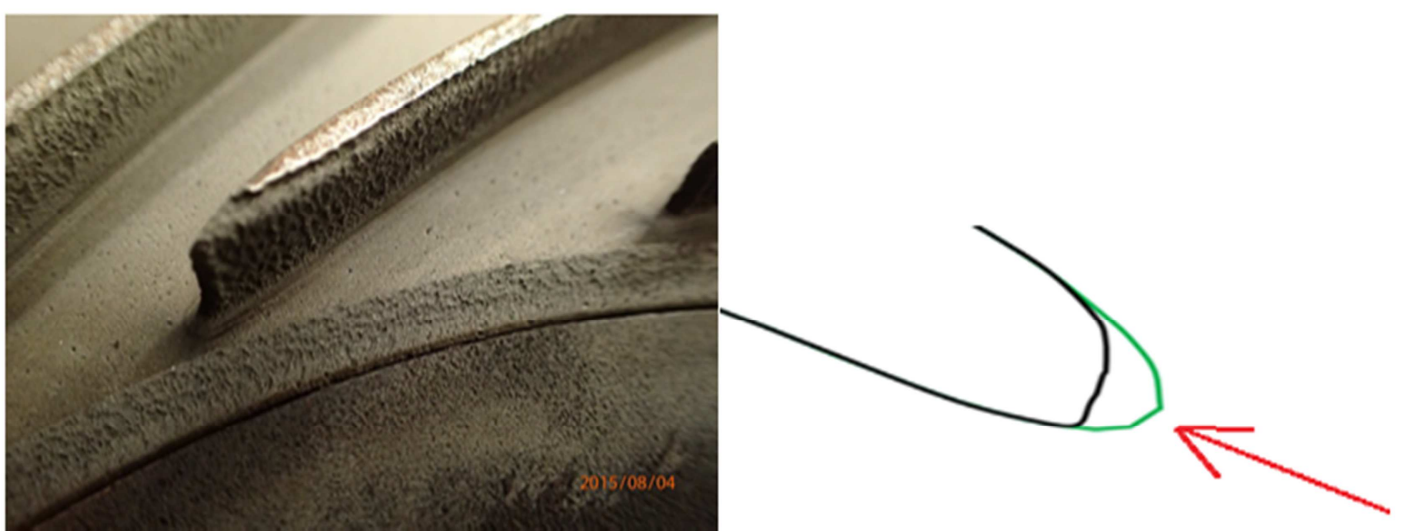

Figure 15. Diffuser after erosion and a CFD model.

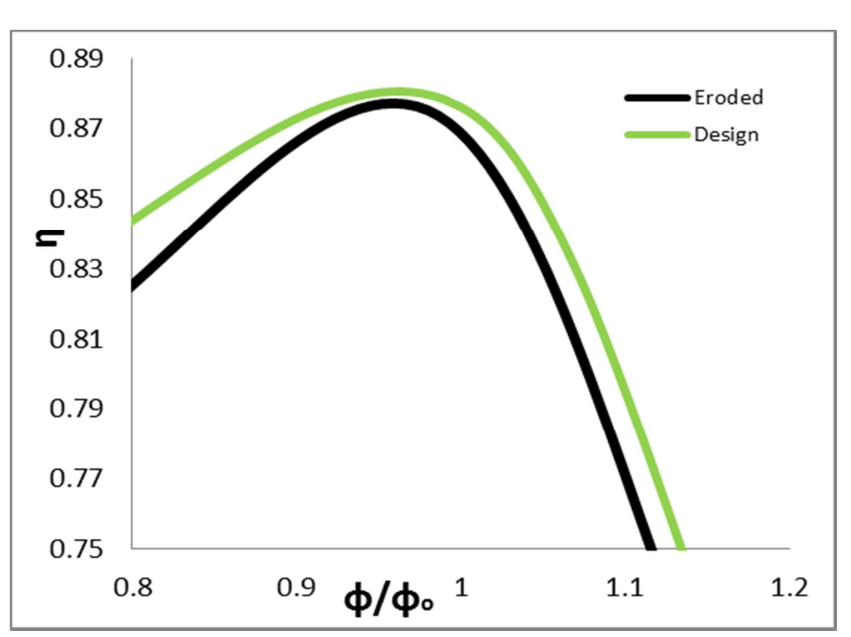

Figure 16. Adibatic efficiency impacts.

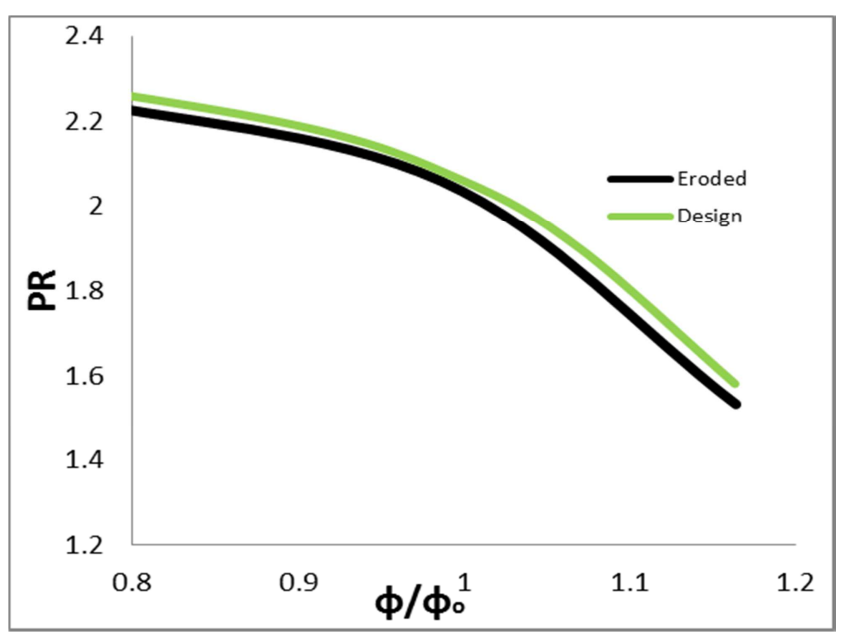

Figure 17. Pressure ratio impacts. 


\section{Conclusions}

CFD and FEA have been extensively used in the design of centrifugal compressors. The usage of modern design tools has been validated to be very beneficial. However, most centrifugal compressor manufactures design procedure and academic studies are based on modifications of a previous design. In this way, some of the design shortcomings are inherited into the new designs. This paper discusses a centrifugal compressor design process that overcomes the traditional design shortage through detail design considerations and full CFD and FAE optimizations. The design process discussed in this study provides the opportunities to design the advanced centrifugal compressor within shorter time.

This paper presented an integrally geared centrifugal compressor design process and considerations that can be a good guidance for future developments and compressor design. The detailed design considerations and design process for centrifugal compressor can reduce the design cycle time without scarifying performance for the new design. The optimizations on compressor aerodynamics and structure performed by CFD and FEA allow the design optimizations in three-dimensional way. The optimizations and design considerations provide a detailed reference document for future centrifugal compressor developments.

\section{Acknowledgements}

This research work is jointly sponsored by Hunan Provincial Natural Science Foundation of China (No. 13JJ8001) and Scientific Research Fund of Hunan Provincial Education Department (No. 16C2296). Authors appreciate reviewers and editors for their comments and suggestions.

\section{Nomenclature}

CFD Computational Fluid dynamics

$\mathrm{C}_{\mathrm{x}} \quad$ Impeller inlet axial velocity, $\mathrm{m} / \mathrm{s}$

$\mathrm{C}_{\mathrm{r} 2} \quad$ impeller exit radial velocity, $\mathrm{m} / \mathrm{s}$

$\mathrm{C}_{\mathrm{s}} \quad$ impeller slip velocity, $\mathrm{m} / \mathrm{s}$

$\mathrm{H} \quad$ Compressor head

IGV Inlet Guide Vane

LCF low cycle fatigue

HCF high cycle fatigue

OEM Original Equipment Manufacturer

$\mathrm{u}_{2} \quad$ Impeller linear velocity

FEA Finite Element Analysis

RANS Reynolds-averaged Navier-Stokes

RPM Rotation per minute

$\mathrm{y}+\quad$ non-dimensional wall distance

$\mathrm{Z} \quad$ the number of blades

$\beta_{2} \quad$ impeller back sweep angle

$\Delta \quad$ Value difference from design or optimal point

$\eta \quad$ Efficiency

$\varphi \quad$ Flow coefficient $=\mathrm{C}_{\mathrm{x}}{ }^{\prime} \mathrm{u}_{2}$

$\mu \quad$ Head coefficient $=\mathrm{H} / \mathrm{u}_{2}{ }^{2}$

\section{References}

[1] C. Xu, Design Experience and considerations for centrifugal compressor development, Journal of aerospace engineering 221 (2007) 273-287.

[2] C. Xu, M. Muller, The design and development of a centrifugal compressor volute, International journal of rotating machinery 2006.

[3] C. Xu, R. S. Amano, Empirical Design Considerations for Industrial Centrifugal Compressors, International Journal of Rotating Machinery, 2012 (2012) 1-16.

[4] C. Xu, R. S., Development of a Low Flow Coefficient Single Stage Centrifugal Compressor, International Journal for Computational Methods in Engineering Science and Mechanics, 10 (2009) $282-289$.

[5] C. Xu, R. S. Amano, 2009, The Development of a Centrifugal Compressor Impeller, International Journal for Computational Methods in Engineering Science and Mechanics, 10 (2009) $290-301$.

[6] C. Xu, R. S. Amano, On the Development of Turbomachine Blade Aerodynamic Design System, International Journal for Computational Methods in Engineering Science and Mechanics, 10 (2009) 186-196.

[7] C. Xu, R. S. Amano, Computational Analysis of Scroll Tongue Shape to Compressor Performance by Using Different Turbulence Models, International Journal for Computational Methods in Engineering Science and Mech, 11 (2010) 85-99.

[8] C. Xu, R. S. Amano, Study of the flow in centrifugal compressor, int. J. of Fluid Machinery and System, 3 (2010) 260-270.

[9] $\mathrm{Xu}, \mathrm{C}$., Impeller for a centrifugal compressor, US Patent. US 7563074 B2 (2005). https://www.google.com/patents/US7563074.

[10] W. F. Castle, Air separation and liquefaction: Recent developments and prospects for the beginning of the new millennium," International Journal of Refrigeration. 25(2002) $158-172$.

[11] C. Xu, R. S. Amano, Effects of Asymmetric Radial Clearance on Performance of a Centrifugal Compressor, ASME Journal Energy Resource Technology, 140 (2017) 052003-0520016, doi:10.1115/1.4038387.

[12] C. Xu, R. S. Amano, Centrifugal Compressor Performance Improvements Through Impeller Splitter Location, ASME Journal Energy Resource Technology 140(2017), 0512010512016, doi: $10.1115 / 1.4037813$.

[13] C. Xu, R. S. Amano, computational Analysis of Scroll Tongue Shape to Compressor Performance by Using Different Turbulence Models, International Journal for Computational Methods in Engineering Science and Mechanics, 11(2010), 85-99.

[14] C. Xu, R. S. Amano, Computational Analysis of Swept Compressor Rotor Blades, International Journal for Computational Methods in Engineering Science and Mechanics, 9 (2008) 374-382.

[15] Fradin, C., Investigation of the Three Dimensional Flow near the Exit of Two Backswept Transonic Centrifugal Impellers, Proc. of the Eighth International Symposium in Air Breathing Engines, (1987) 149 -155. 
[16] C. Xu, R. S. Amano, Centrifugal compressor design impacts: lean and meridional shape, GT2013-9411, (2013).

[17] C. Xu, R. S. Amano, On the Development of Turbine Blade Aerodynamic Design System, 2001-GT-0443 (2001).

[18] C. Xu, R. S. Amano, Meridional considerations of the centrifugal compressor development, International Journal of Rotating Machinery, (2012), 1-11, doi:10.1155/2012/518381.

[19] C. Xu, R. S. Amano, Performance impacts of centrifugal compressor splitter location, GT2016-56017, (2014).

[20] C. Xu, R. S. Amano, Aerodynamic and structure considerations in centrifugal compressor design-blade lean effects, GT2012-68027 (2012).
[21] F. J. Wiesner, A review of slip factors for centrifugal impellers, ASME J. of Eng for Power, 89 (1969), 558-572.

[22] ANSYS Inc., Ansys version 15, ANSYS, Inc, 275 Technology Drive, Canonsburg, PA 15317, (2013).

[23] ANSYS Inc., ANSYS mechanical APDL Structural Analysis Guide, ANSYS, Inc, 275 Technology Drive, Canonsburg, PA 15317,(2013).

[24] AK Steel, 17-4 PH stainless steel, AK steel Corp, West Chester, OH (2007). 